\title{
O PROUNI na educação superior brasileira: indicadores de acesso e permanência
}

\author{
Danielle Dias da Costa \\ Norma-Iracema de Barros Ferreira
}

Resumo: O estudo avalia em que medida o PROUNI expande o acesso à Educação Superior, identificando as condições de ingresso, matrícula, custo-aluno e permanência por meio do Índice de Conclusão de Curso, numa escala nacional. A abordagem foi quanti-qualitativa, com levantamento documental no Portal INEP, Sisprouni e dados da Receita Federal. Os resultados apontam que o PROUNI foi responsável por aumentar as matrículas no setor privado em uma média anual de 5,15\%. O custo-aluno foi em média R\$ $3.381,43 /$ anual ou $\mathrm{R} \$ 281,78 /$ mês por bolsista. A ociosidade das bolsas foi em média de $30 \%$ e a evasão foi na ordem de $10,4 \%$, provavelmente em função das restrições econômicas dos estudantes.

Palavras-chave: PROUNI. Expansão. Acesso. Permanência.

\section{PROUNI (University for All Program) in Brazilian Higher Education: indicators of access and permanence}

Abstract: The study assesses the effects of PROUNI on access to higher education, identifying the conditions of admission, enrollment, cost-student and endurance, through the rate of course conclusion, in a national scale. The research was quantitative-qualitative approach with documentary survey in INEP Portal, Sisprouni and IRS data. The results indicate that PROUNI was responsible for increasing enrollments in the private sector by an annual average of $5.15 \%$. The cost-student was on average R $\$ 3,381.43 /$ year or R $\$ 281.78 /$ month per student. The idleness of scholarships averaged $30 \%$ and the college dropout was around $10.4 \%$, probably due to students' economic constraints.

Key words: PROUNI. Expansion. Access. Endurance. 


\section{Introdução}

A restrição do acesso e as condições de permanência desfavoráveis na Educação Superior são dois problemas significativos no contexto brasileiro. Isso se agrava quando estudantes devem superar "barreiras," quase instransponíveis, para ingressar nas reduzidas vagas das universidades públicas, se comparadas ao amplo número daquelas oferecidas no setor privado. Um desses condicionantes decorre dos processos seletivos concorridos e reconhecidamente excludentes, o que contribui para limitar o acesso a este nível de ensino. Essas condições acentuam o processo de desigual distribuição dos bens educacionais, assim como vêm impor exigências ao estudante, seja das camadas populares ou não, os quais podem vir a ser impedidos de ingressar e, principalmente, concluir a formação no Curso superior.

Mediante tal situação, nas últimas décadas, o Governo Federal tem recorrido à criação de medidas para expansão quantitativa, do acesso à Educação Superior. Durante o Governo Lula, por exemplo, foram criadas políticas como o Plano de Reestruturação e Expansão das Universidades Federais (REUNI), em 2007, o Programa Universidade para todos (PROUNI) em 2004, além do Financiamento Estudantil (FIES), que tangenciam para tal. Em relação à pauta de políticas direcionadas às camadas populares, como é o caso do PROUNI e FIES, durante o Governo Dilma, também se aprovou a política de cotas, no ano de 2012, em forma de Lei n. 12.711/2012.

Todas as medidas citadas podem ser usadas para estimar e problematizar a influência macroeconômica sobre as políticas educacionais, tanto que é possível por meio de estudos dessa natureza, avaliar os caminhos adotados pelo Executivo e suas correlações de força envolvidas. Assim, podem-se explicitar atores, interesses e objetivos que revestem as políticas educacionais, incluindo as de expansão de acesso para todos os níveis de ensino, que, todavia, no presente estudo é específico à Educação Superior.

Vale ressaltar que as ações, programas e leis que visam ampliar o acesso à Educação Superior, principalmente o das camadas populares, são objetos de constante discussão. No intuito de avaliar o papel destas medidas voltadas ao discurso da justiça social como ora publicitado pelo Governo e assim como entendido por parte da população, apresenta-se o presente estudo, visando suprir a necessidade de investigações que analisem em profundidade os resultados de uma das medidas adotadas no referido nível de ensino.

Sendo assim, este estudo objetiva averiguar uma das principais políticas, o PROUNI, quanto a objetivos e resultados, considerando determinados indica- 
dores, como: isenção fiscal, custo-aluno, número de matrículas, tipo de bolsa e condições dos Cursos, associado aos fenômenos que integram esse processo, no sentido de avaliar a contribuição do Programa, referente ao acesso e às condições de permanência na Educação Superior no Brasil, entre 2006 e 2014. Trata-se de uma pesquisa de abordagem quanti-qualitativa, com levantamento documental no Portal INEP, Sisprouni e dados da Receita Federal, Tribunal de Contas da União (TCU) e Controladoria-Geral da União (CGU), assim como dialoga com pesquisas na área da Educação Superior.

\section{PROUNI: condições de acesso, seleção e isenção fiscal nas IES parceiras}

O PROUNI foi criado pela Lei n. 11.096/2005 (BRASIL, 2005), regulamentada pelo Decreto n. 5.493, de 18 de julho de 2005. Segundo os termos do Programa, para se candidatar a uma bolsa, o estudante deve ter atendido aos seguintes requisitos: participação no Exame Nacional do Ensino Médio (ENEM), referente à edição imediatamente anterior ao processo seletivo; obtenção de nota mínima estabelecida pelo Ministério da Educação (MEC); usufruto de renda familiar, por pessoa, de até três salários mínimos. Somam-se outras condições relacionadas no Artigo $2^{\circ}$ da Lei:

Ter cursado o ensino médio completo em escola pública, ou; ter cursado o ensino médio completo em escola privada com bolsa integral da instituição, ou; ser pessoa com deficiência, ou; ser professor da rede pública de ensino básico, em efetivo exercício, integrando o quadro permanente da instituição e concorrendo a vagas em cursos de Licenciatura, Normal Superior ou Pedagogia. Neste último caso, a renda familiar por pessoa não é considerada.

Na forma da Lei, observa-se que o PROUNI propicia acesso, todavia um das questões mais expoentes diz respeito à isenção fiscal que é concedida às Instituições de Ensino Superior (IES), de natureza privada, tal como o Programa possibilita. Os estudos de Carvalho (2005) sintetizados no Quadro 1 ilustram bem essa dispensa de tributos: 
Quadro 1 - Alíquotas e base de cálculo dos tributos federais, por categoria de IES no Brasil (2005)

\begin{tabular}{|c|l|c|c|c|c|c|}
\hline \multirow{2}{*}{ Tributos } & \multicolumn{2}{|c|}{ Lucrativa } & \multicolumn{2}{c|}{$\begin{array}{c}\text { Confessional/ } \\
\text { Comunitária }\end{array}$} & \multicolumn{2}{c|}{ Filantrópica } \\
\cline { 2 - 7 } & \multicolumn{1}{|c|}{ Atual } & PROUNI & Atual & PROUNI & Atual & PROUNI \\
\hline IRPJ & $25 \%$ lucro & - & - & - & - & - \\
\hline CSSLL & $9 \%$ lucro & - & - & - & - & - \\
\hline COFINS & $7,6 \%$ receita & - & $3 \%$ receita & - & - & - \\
\hline PIS & 1,65 receita & - & $1 \%$ receita & - & $1 \%$ receita & - \\
\hline $\begin{array}{c}\text { INSS } \\
\text { (patronal) }\end{array}$ & $20 \%$ folha & $20 \%$ folha & $20 \%$ folha & $20 \%$ folha & - & - \\
\hline
\end{tabular}

Fonte: CARVALHO, Cristina H. A.; LOPREATO, Francisco L. C. Finanças públicas, renúncia fiscal e o PROUNI no governo Lula. Impulso, Piracicaba, v. 16, n. 40, p. 93-104, maio/ago. 2005.

Pelo quadro apresentado, é importante notar que a incidência de tributos varia conforme categoria institucional de cada IES. Isso diversifica os valores da isenção fiscal, afinal o valor da renúncia dependerá do nível de adesão e do tipo de instituição que vier a participar do Programa. Esse formato de arrecadação faz com que as finanças públicas sofram como impacto principal, a redução potencial da receita tributária (CARVALHO, 2005). Antes de tratar sobre os valores correspondentes à isenção fiscal, o Quadro 2 a seguir, elucida a quantidade de IES privadas, com e sem fins lucrativos, sendo estas as prováveis parceiras do PROUNI, já que a adesão é facultativa:

Quadro 2 - IES: com fins lucrativos e Comunitárias/Confessionais/Filantrópicas no Brasil (2005-2009)

\begin{tabular}{|c|c|c|c|}
\hline Ano & Com Fins Lucrativos & $\begin{array}{c}\text { Comunitárias/ } \\
\text { Confessionais/ } \\
\text { Filantrópicas }\end{array}$ & Total de IES \\
\hline $\mathbf{2 0 0 5}$ & 1.520 & 414 & 1.934 \\
\hline $\mathbf{2 0 0 6}$ & 1.583 & 439 & 2.022 \\
\hline $\mathbf{2 0 0 7}$ & 1.594 & 438 & 2.032 \\
\hline $\mathbf{2 0 0 8}$ & 1.579 & 437 & 2.016 \\
\hline $\mathbf{2 0 0 9}$ & 1.779 & 290 & 2.069 \\
\hline
\end{tabular}

Fonte: Sinopse Estatística da Educação Superior (BRASIL.INEP, 2005, 2006, 2007, 2008 e 2009). 
Dentre as categorias administrativas das IES, à exceção das públicas, as instituições mais beneficiadas por aderirem ao PROUNI são as com fins lucrativos, que em 2009 totalizavam 1.779, em detrimento das IES filantrópicas, confessionais e comunitárias, com apenas 290 instituições. Isso representa uma quantidade de renúncia, potencialmente significativa, pois as IES com fins lucrativos:

[...] ficam isentas, a partir da adesão [ao PROUNI], de praticamente todos os tributos que recolhiam. Além disso, a contrapartida em número de bolsas é muito baixa, pois permanecem com o mesmo status institucional e continuam não se submetendo à fiscalização/ regulação governamental (CARVALHO, 2005, p. 13).

Portanto, com o número elevado de IES que aderiram ao PROUNI até 2008, somadas em 1.400 distribuídas em todo o território nacional (BRASIL, 2008), dentre as 2.016 IES privadas existentes, a isenção fiscal gerada pela renúncia dos tributos não é um montante desprezível, correspondendo a 69,4\%. Com dados mais atualizados em relação à isenção fiscal, a seguir cabe destacar o montante da isenção fiscal, conforme dados das autoras, na página a seguir.

De acordo o Quadro 3, o valor de R \$ 3.621.382.027,00 (três bilhões, seiscentos e vinte e um milhões, trezentos e oitenta e dois mil e vinte e sete Reais) corresponde ao volume de isenção fiscal decorrente do PROUNI. Isso significa a não arrecadação, por parte da União, das contribuições do IRPJ, CSSLL, COFINS, PIS/PASEP, entre os anos de 2006 a 2012. Sobre este aspecto, os efeitos dessa renúncia fiscal, pela óptica financeira, incentivam a expansão do setor privado e implicaram em não embolso dos tributos que compõem o Fundo Público Federal (FPF), o qual financia as atividades essenciais prestadas pelo Estado à sociedade.

Para avaliar a dimensão do montante da isenção fiscal do PROUNI até 2012, recorre-se aos estudos de Amaral (2011) sobre o financiamento das Instituições Federais de Educação Superior (IFES). O autor apresenta que R \$ 3.461.574,83 (três bilhões, quatrocentos e sessenta e um milhões, quinhentos e setenta e quatro Reais e oitenta e três centavos) correspondem ao montante de recursos financeiros totais, de todas as fontes, aplicados nas 94 IFES em 2009, sendo esse valor correspondente a $0,72 \%$ do Produto Interno Bruto (PIB) brasileiro, naquele ano. Portanto, o valor da isenção fiscal acumulada com o PROUNI, que fica retida nas IES privadas seria capaz de financiar integralmente o sistema da Educação Superior federal em 2009, ainda obtendo um saldo de R\$160 milhões de Reais, caso a isenção fosse repassada às IFES. 


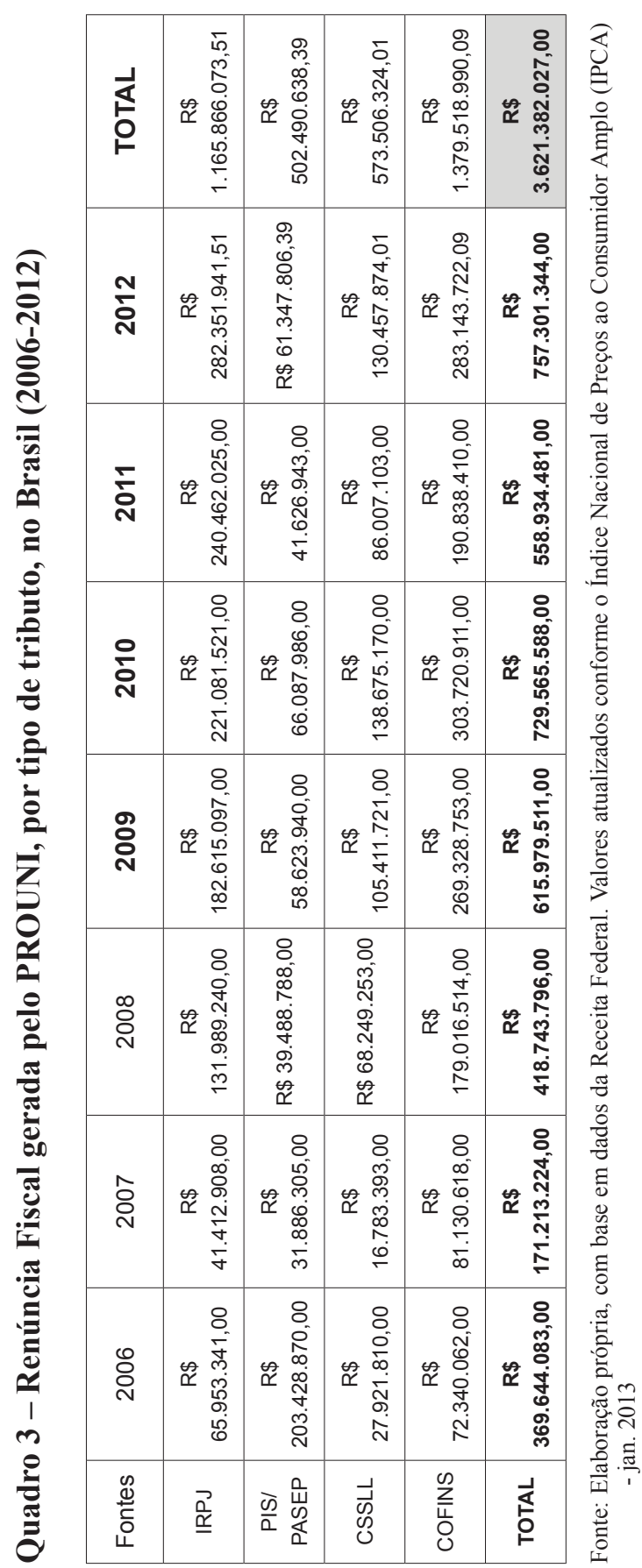


Nesse sentido, o valor embolsado pelo setor privado decorrente do Programa reitera o fato de existir, por parte do Governo Federal, incentivo e uma espécie de estímulo para expansão e manutenção do sistema da educação privada, mantendo os lucros na própria Instituição ou os chamados oligopólios educacionais (CHAVES, 2010). Além disso, serve como uma forma complementar de diminuir as pressões pelo aumento dos gastos públicos com a Educação Superior, ao se criar vagas públicas nas IES privadas, via PROUNI, dando a impressão de maiores oportunidades educacionais aos estudantes que prestam a seleção para nele ingressar.

No tocante à isenção fiscal e ao seu benefício disso às IES privadas, os pesquisadores Lima, Prado e Vieira (2011) alertam para o tipo de instituições contempladas com isenção fiscal. As que podem ser consideradas as maiores beneficiadas ao ofertar as bolsas do PROUNI, em maior grau, trata-se do setor das Instituições de Ensino Superior com fins lucrativos que contabilizou 294.365 (49\%) bolsistas em 2009. Seguem-se as entidades beneficentes de assistência social, com 171.069 bolsistas (29\%); e as instituições sem fins lucrativos não beneficentes isentas, com o total de bolsistas e a porcentagem correspondente: 130.282 (22\%), de acordo com os dados do SISPROUNI (BRASIL, 2005-2009).

Sobre a isenção fiscal e a efetividade do preenchimento das bolsas PROUNI, é oportuno ressaltar uma problemática que foi detectada nas IES privadas: a ociosidade de bolsas, em contrapartida de isenção fiscal integral dos tributos previstos pela adesão ao PROUNI por parte das IES. Esta questão foi objeto de investigação por meio de auditoria realizada pelo Tribunal de Contas da União, em 2009 (BRASIL, 2009).

A referida ação do TCU desencadeou um processo de alterações legislativas, principalmente trazidas pelo Art. 26 da Lei 12.431/2011, que introduziu o mecanismo de proporcionalidade na isenção fiscal, com base na ocupação efetiva das bolsas devidas, no âmbito do PROUNI. Segundo o Tribunal esta medida deveria gerar, em 2013, uma economia de aproximadamente R $\$ 303,5$ milhões (BRASIL, 2013), montante que não estava sendo revertido em acesso, objetivo maior e justificativa utilizada para a isenção fiscal concedida às IES.

Por conseguinte, em vista da análise a isenção fiscal, o Programa torna-se um instrumento que beneficia principalmente as IES com fins lucrativos, fazendo com que contribua para redefinição do papel do Estado na oferta da Educação Superior (MANCEBO, 2004). Com estímulos à privatização nesse setor, a redefinição ocorre em função de se dar primazia à racionalidade econômica de curto prazo, por meio de políticas focalizadas, quando é patente que o Governo prefere "comprar" vagas em instituições privadas a criar o mesmo número delas, nas IES de sua responsabilidade direta - universidades públicas. 


\section{PROUNI: indicadores de avaliação do acesso e permanência, no Brasil}

\section{- Indicadores de acesso no PROUNI}

Para obter o indicador de acesso ao PROUNI considerou-se para esse cálculo o total de bolsas ocupadas via PROUNI, quantidade pouco representativa, em 2005, ano que inicia o Programa, e que se ampliou gradativamente entre de $2 \%$ e $3 \%$, anualmente, chegando a 2012 com 7,3\% de bolsas ocupadas, em relação ao número de matrículas existentes no setor privado, no Brasil. Conforme Guerra e Fernandes (2009) o advento do Programa aumentou o número de bolsistas do PROUNI no setor privado, contribuindo para diminuir o problema crônico das instituições privadas: o alto número de vagas ociosas. No Quadro 4 consta o percentual da representatividade do número de bolsistas PROUNI em relação ao número de matrículas na Educação Superior privada, Brasil, no período 2005-2012:

Quadro 4 - Percentual sobre o número de bolsas PROUNI ocupadas em relação ao número de matrículas na Educação Superior privada no Brasil (2005-2012)

\begin{tabular}{|c|c|c|c|}
\hline Ano & $\begin{array}{c}\text { N. de matrículas em } \\
\text { IES privadas }\end{array}$ & Bolsas PROUNI ocupadas & $\begin{array}{c}\% \text { de Bolsas sobre o } \\
\text { número total de matrículas }\end{array}$ \\
\hline $\mathbf{2 0 0 6}$ & 3.632 .987 & 109.009 & $3,0 \%$ \\
\hline $\mathbf{2 0 0 8}$ & 4.255 .064 & 124.607 & $2,9 \%$ \\
\hline $\mathbf{2 0 1 0}$ & 4.736 .001 & 152.697 & $3,2 \%$ \\
\hline $\mathbf{2 0 1 2}$ & 5.191 .957 & 379.330 & $7,3 \%$ \\
\hline
\end{tabular}

Fonte: Elaboração própria, com base no Censo da Educação Superior (2005-2010) e dados do Portal do PROUNI (SESU/MEC).

Os dados presentes no Quadro 4 remetem ao teor do Quadro 5, para fins de estimativa, que trata do percentual da representatividade do tipo de bolsa PROUNI ofertadas. Isso não quer dizer que estejam ocupadas, em relação ao número de matrículas na Educação Superior privada: 
Quadro 5 - Percentual da representatividade do número de bolsas PROUNI ofertadas por tipo de bolsa, na Educação Superior privada no Brasil (2005-2014)

\begin{tabular}{|l|c|r|r|r|r|}
\hline Ano & $\begin{array}{c}\text { Privada } \\
\text { (pagantes + } \\
\text { bolsistas + FIES) }\end{array}$ & $\begin{array}{c}\text { Bolsas } \\
\text { PROUNI } \\
\text { (integral) }\end{array}$ & $\begin{array}{c}\text { Bolsas } \\
\text { PROUNI } \\
\text { (parcial) }\end{array}$ & $\begin{array}{c}\text { \% bolsas } \\
\text { (integral) }\end{array}$ & $\begin{array}{c}\% \text { bolsas } \\
\text { (parcial) }\end{array}$ \\
\hline $\mathbf{2 0 0 5}$ & 3.321 .095 & 71.905 & 40.370 & $2,1 \%$ & $1,2 \%$ \\
\hline $\mathbf{2 0 0 6}$ & 3.632 .987 & 98.698 & 39.970 & $2,7 \%$ & $1,1 \%$ \\
\hline $\mathbf{2 0 0 7}$ & 3.914 .970 & 97.631 & 66.223 & $2,4 \%$ & $1,69 \%$ \\
\hline $\mathbf{2 0 0 8}$ & 4.255 .064 & 99.495 & 125.510 & $2,3 \%$ & $2,9 \%$ \\
\hline $\mathbf{2 0 0 9}$ & 4.430 .157 & 153.126 & 94.517 & $3,4 \%$ & $2,1 \%$ \\
\hline $\mathbf{2 0 1 0}$ & 4.736 .001 & 125.922 & 115.351 & $2,6 \%$ & $2,4 \%$ \\
\hline $\mathbf{2 0 1 1}$ & 5.140 .312 & 129.672 & 124.926 & $2,5 \%$ & $2,4 \%$ \\
\hline $\mathbf{2 0 1 2}$ & 5.191 .957 & 150.870 & 133.752 & $2,9 \%$ & $2,5 \%$ \\
\hline $\mathbf{2 0 1 3}$ & 5.421 .639 & 164.379 & 87.995 & $3,0 \%$ & $1,6 \%$ \\
\hline $\mathbf{2 0 1 4}$ & 5.926 .458 & 205.237 & 101.489 & $3,4 \%$ & $1,7 \%$ \\
\hline
\end{tabular}

Fonte: Elaborado pelas autoras, com base nos Censos da Educação Superior e Portal SISPROUNI.

No Quadro 5, que trata da quantidade de bolsa por modalidade integral e parcial, verifica-se uma maior proporção de bolsas integrais, em relação às parciais, entretanto, a partir de 2007 é perceptível nas instituições particulares a diminuição da diferença e até mesmo a superação do número de bolsas parciais em relação a de bolsas integrais. Registra-se da análise, que entre 2005 e 2007 e 2013 e 2014, estes dois últimos anos é o momento em que se constata um maior distanciamento entre a representatividade de bolsas integrais em detrimento das parciais. A partir do período de 2008 a 2012, existe um crescimento no número de bolsas parciais, o qual reforça a tese de que esta modalidade auxilia as IES privadas a captar mais alunos e a flexibilizar a composição de suas receitas, ao acessar $50 \%$ das mensalidades desses bolsistas. Isso demonstra que o setor privado, por meio da bolsa parcial, obtém uma via que pode possibilitar a ampliação do lucro, buscando arrecadar mais receita propiciada pelo número de bolsistas (GUERRA; FERNANDES, 2009).

Para mensurar o valor de financiamento das bolsas PROUNI, nesta pesquisa optou-se em utilizar como indicador o custo-aluno, com base na seguinte equação: o valor da isenção fiscal dividido pelo número de bolsas ocupadas, independentemente de seu tipo, haja vista os números apresentados no Relatório do Tribunal de Contas da União (BRASIL, 2009). Sendo assim, o valor obtido consta na Tabela 1: 


\section{Tabela 1 - Valor por bolsista obtido da relação entre o número de bolsas ocupadas e isenção fiscal do PROUNI, no Brasil (2005-2012)}

\begin{tabular}{ccccc}
\hline Ano & $\begin{array}{c}\text { Bolsas } \\
\text { ocupadas }\end{array}$ & Isenção fiscal & $\begin{array}{c}\text { Custo anual } \\
\text { bolsista }\end{array}$ & $\begin{array}{c}\text { Custo mensal por } \\
\text { bolsista }\end{array}$ \\
\hline 2006 & 109.009 & $\mathrm{R} \$ 369.644 .083,00$ & $\mathrm{R} \$ 3.390,95$ & $\mathrm{R} \$ 282,57$ \\
2008 & 124.607 & $\mathrm{R} \$ 418.743 .796,00$ & $\mathrm{R} \$ 3.360,51$ & $\mathrm{R} \$ 280,04$ \\
2010 & 152.697 & $\mathrm{R} \$ 729.565 .588,00$ & $\mathrm{R} \$ 4.777,86$ & $\mathrm{R} \$ 398,15$ \\
2012 & 379.330 & $\mathrm{R} \$ 757.301 .344,00$ & $\mathrm{R} \$ 1.996,41$ & $\mathrm{R} \$ 166,36$ \\
\hline
\end{tabular}

Fonte: Elaboração própria, com base na Receita Federal (2006-2010), Relatório do TCU (2009) e Relatório CGU (2015). Valores atualizados com o IPCA-2013.

A Tabela 1 expõe que em 2006, o custo-aluno anual do bolsista PROUNI era de $\mathrm{R} \$ 3.390,95$ e em 2012 diminuiu para $\mathrm{R} \$ 1.996,41$. Convertendo os valores, para mensalidade, o custo-aluno no ano de 2006 corresponde a R\$ 282,57 e em 2012 equivale a R \$ 166,365, por Bolsa ocupada. Entre os anos de 2008 e 2010, verifica-se que o valor do custo-aluno PROUNI mensal equivale às mensalidades praticadas nos Cursos menos onerosos ocupados por tais estudantes, os quais são os mais ofertados pelo Programa, conforme o Quadro 6 que será apresentado adiante. O fato de o custo-aluno PROUNI em 2012 perfazer $\mathrm{R} \$ 166,36$ reforça o caráter economicista que o Programa assume, quando se verifica o quanto se aplica via isenção fiscal para a abertura de uma vaga na Educação Superior privada.

Os dados correspondentes ao custo-aluno PROUNI, neste estudo, diferem em parte dos cálculos realizados pelo TCU e pelo MEC. A explicação disso, é a equação utilizada que contemplou como variáveis: o montante da isenção fiscal decorrente do PROUNI, que consta nos Demonstrativos das despesas tributárias emitidos pela Receita Federal, entre os anos de 2006 a 2010, com os valores atualizados conforme o Índice Nacional de Preços ao Consumidor Amplo (IPCA) de janeiro de 2013, dividido pelo número de bolsas ocupadas, independentemente do seu tipo. Essa última variável é consoante à utilizada pelo TCU, quando realiza investigação quanto à operacionalização do Programa. Isso porque se buscou um cálculo capaz de obter indicador fidedigno aos dados que constam nos referidos documentos.

Cabe destacar que, nesse sentido, são comuns as divergências de cálculo, haja vista que até mesmo isso foi alvo de embates entre o TCU e o MEC, tanto que essa matéria foi motivo de polêmica, pois em 2009: 
Usando dados fornecidos pela Receita, o TCU concluiu que o custo médio das bolsas do PROUNI, em 2006, era de R \$ 601,00 mensais, maior do que as mensalidades cobradas na época: $\mathrm{R} \$ 499,00$. O MEC contestou o dado, apresentando cifra bem menor: $\mathrm{R} \$ 150,00$. $\mathrm{Na}$ raiz da divergência, estão as bolsas ociosas - para o Ministério da Educação, o valor da renúncia deve levar em conta o total de bolsas oferecidas, já o Tribunal considera as efetivamente ocupadas (FABRINI; WEBER, 2011).

Dando continuidade, para mensurar e comparar o valor investido na vaga do bolsista PROUNI e o que é destinado àqueles que ingressam nas IES públicas, convém apresentar a Tabela 2:

Tabela 2 - Histórico da estimativa do investimento público direto por estudante, na Educação Superior, anual e mensal, no Brasil (2000-2013)

\begin{tabular}{ccc}
\hline \multirow{2}{*}{ Ano } & \multicolumn{2}{c}{ Custo-aluno na Educação Superior (R\$) } \\
\cline { 2 - 3 } 2000 & $\mathrm{R} \$ 8.849,00$ & Mensal \\
2001 & $\mathrm{R} \$ 9.416,00$ & $\mathrm{R} \$ 737,41$ \\
2002 & $\mathrm{R} \$ 9.813,00$ & $\mathrm{R} \$ 784,66$ \\
2003 & $\mathrm{R} \$ 9.372,00$ & $\mathrm{R} \$ 817,75$ \\
2004 & $\mathrm{R} \$ 9.547,00$ & $\mathrm{R} \$ 781,00$ \\
2005 & $\mathrm{R} \$ 10.872,00$ & $\mathrm{R} \$ 795,58$ \\
2006 & $\mathrm{R} \$ 11.609,00$ & $\mathrm{R} \$ 906,00$ \\
2007 & $\mathrm{R} \$ 12.813,00$ & $\mathrm{R} \$ 967,41$ \\
2008 & $\mathrm{R} \$ 12.542,00$ & $\mathrm{R} \$ 1.067,75$ \\
2009 & $\mathrm{R} \$ 14.694,00$ & $\mathrm{R} \$ 1.045,16$ \\
2010 & $\mathrm{R} \$ 16.541,00$ & $\mathrm{R} \$ 1.224,50$ \\
2011 & $\mathrm{R} \$ 18.770,00$ & $\mathrm{R} \$ 1.378,41$ \\
2012 & $\mathrm{R} \$ 18.044,00$ & $\mathrm{R} \$ 1.564,16$ \\
2013 & $\mathrm{R} \$ 21.383,00$ & $\mathrm{R} \$ 1.503,66$ \\
\hline
\end{tabular}

Fonte: Elaboração das autoras. Adaptado de INEP/MEC, com valores nominais.

Com base nos valores apresentados nas Tabelas 1 e 2, é possível comparar o custo-aluno PROUNI e o valor dos recursos aplicados, por estudante, no sistema federal de ensino. Os dados revelam que os recursos financeiros aplicados para 
arcar com o estudante que ingressa na Educação Superior pública, são muito superiores ao destinado via PROUNI.

Um aspecto a se ressaltar sobre o valor do custo-aluno PROUNI, é o fato de vir a ser superior aos apresentados na Tabela 1, considerando que das bolsas ocupadas, no caso das parciais, existe a co-participação do bolsista para arcar com sua permanência. Afinal, quando contemplado com bolsa parcial, o estudante deve desembolsar 50\% da mensalidade do Curso, representando que além da isenção fiscal, as IES arrecadam mais receita com os bolsistas parciais, o que corresponde um incremento nos lucros.

De acordo com os dados, ainda é patente que o valor do custo-aluno PROUNI investido pelo Poder Público, nas IES privadas, tem sido inferior ao investido nas IFES, decorrente de alguns fatores que devem ser considerados: a) não se inclui, ou há poucos bolsistas nos Cursos mais caros; b) desconsideram-se os bolsistas parciais, ao usá-los no cálculo como integrais; c) oferta-se uma formação com baixo envolvimento em pesquisa, sem oportunidades de exercício de monitoria, extensão, Iniciação Científica; d) ocorre baixo investimento em Pós-Graduação stricto sensu. Portanto, tal montante de atividades/possibilidades complementa e qualifica a formação do acadêmico, quando inserido nas IFES, as quais consequentemente custam mais caro aos cofres públicos, o que não é nenhum demérito, mas sim característica peculiar a uma educação de qualidade, que onera em nome do fortalecimento da tríade ensino/pesquisa/extensão.

Quanto à democratização empregada no discurso do PROUNI e em sua consecução, aponta-se que a medida emergencial de ampliar o acesso, com um número residual de vagas da Educação Superior, mesmo no setor privado, em termos quantitativos contribui para um incremento do ingresso e do número de jovens nesse nível de ensino. Entretanto, a qualidade desta formação é algo que deve ser questionado, considerando a afirmação de Leher (2010, p. 383384): "a maior parte desses jovens ingressou não em universidades, mas em escolões de baixíssima qualidade; muitos, inclusive, farão cursos sequenciais e tecnológicos de curta duração, modalidades aligeiradas de ensino dito superior". Desta maneira, o Programa torna-se uma medida paliativa, de efeitos duvidosos, principalmente, configura um carreamento de verbas públicas para o ensino privado - uma lamentável distorção na política de investimento na Educação Superior, patrocinada pelo Governo Federal.

Quando se trata da qualidade dos Cursos, a afirmação de Leher (2010) procede ao se ratificar que em 2007, denunciou-se que dos 923 Cursos superiores com notas baixas no Exame Nacional de Desempenho de Estudantes (ENADE), 
462 tinham bolsas do PROUNI para o segundo semestre daquele ano, o que representava 8\% das 5,8 mil bolsas oferecidas nos Cursos de Graduação para os bolsistas. As notas baixas foram consecutivas após de três anos de avaliações, em que o MEC descobriu que quase mil cursos tiveram resultados insatisfatórios no ENADE e metade dessas faculdades oferecia bolsas do PROUNI, na época. Conforme levantamento feito por Castro e Mariz (2013) em 2013 esses casos ainda eram recorrentes, tanto que quatro em cada dez vagas com bolsa de estudo do PROUNI ofertadas em IES privadas advinham de instituições avaliadas pelo MEC com notas insatisfatórias.

Ainda sobre as condições do acesso e a qualidade dos Cursos (CASTRO; MARIZ, 2013), pode-se afirmar que, 40\% das 2.566 Graduações com Bolsa PROUNI, em 2013, possuíam notas insatisfatórias nas últimas avaliações. Em termos numéricos, isso representava que do total de 1.044 Graduações com menções baixas, de 1 ou 2 numa escala de até 5, no Conceito Preliminar do Curso (CPC), estão na lista do PROUNI. Ressalta-se que algumas chegam a oferecer mais de 100 vagas. O número de Cursos nessa situação representa $8,5 \%$ do total ofertado na edição do Programa daquele ano, ou seja, sendo disponíveis 12.159 bolsas.

Além disso, cabe destacar que o Programa como política focalizada para as camadas populares nesses termos acentua restrições, as quais se devem ao fato de estar distante de implementar e diminuir a causa do problema: a estratificação escolar e número insuficiente de vagas para Educação Superior nas IES públicas. Tais problemas acentuam a condição de exclusão de milhares de jovens que concluem o Ensino Médio e aspiram pela Educação Superior, à medida que a Educação Básica, também com problemas estruturais, acaba por reproduzir obstáculos aos estudantes para que concorram em par de igualdade a seleções e processos seletivos, permanecendo inalterada a situação de exclusão das camadas populares.

Face ao exposto, isto contribui com um processo que se chama discriminação positiva, de prever a destinação de vagas a estudantes das camadas populares no setor privado, a qual segundo Mancebo (2004) é uma forma para ingresso que merece crítica. Segundo a autora, tal medida está longe de resolver ou de corrigir a distribuição desigual dos bens educacionais. O problema do acesso então se incrementa, pois a privatização implantada pelo Programa nesses moldes tende a aprofundar as condições históricas de discriminação e de negação do direito à Educação Superior a que são submetidos os setores populares.

Ao tratar sobre o processo de seleção para obter a bolsa PROUNI, recorrendo à nota obtida no ENEM, é possível notar que tais escores acabam por 
desfavorecer os estudantes das camadas populares, ao concorrer com muitos candidatos, no momento da grande procura por bolsas em instituições reconhecidas por sua excelência acadêmica. Partindo disso, emerge a questão do mérito e, ao mesmo tempo, o problema do acesso, à proporção que:

[...] o ensino superior se abriu na realidade a estratos sociais e a públicos menos tradicionais neste nível de ensino; contudo, permanecem acentuadas assimetrias sociais nas instituições e nos cursos a que se tem acesso, ao mesmo tempo em que a permanência e abandono também se diferenciam socialmente em termos das respectivas taxas de incidência. Estes fenômenos têm causas diversas, não sendo possível ilibar as próprias instituições de ensino superior de responsabilidades nesse cenário (ALMEIDA et al., 2012, p. 899).

Quanto às condições desfavoráveis aos alunos que ingressam pelo PROUNI, essas constituem um denominador que contesta o discurso de democratização que o reveste, sustentado pela retórica do acesso de jovens de baixa renda ao ensino superior (PEREIRA FILHO, 2011). Afinal, é oportuno defender que a democratização substancial pode ser quando o ensino público de nível médio possibilitar a todos os estudantes, independente de sua condição social, concorrerem com aprovação às vagas dos Cursos mais tradicionais das melhores IES públicas.

Quanto o acesso das camadas populares à Educação Superior, convém remeter a discussão de autores como Zago (2006), a qual debate sobre a problemática que assola a presença das camadas populares, sem condições de permanência e de escolha sobre a sua vida acadêmica, nomeando esse fenômeno como a “exclusão dos incluídos." Conceitualmente, Almeida et al. (2012) explica que isso ocorre quando o estudante consegue ter acesso à Educação Superior, mas tem inúmeras dificuldades para se manter nesse nível de ensino, respondendo às expectativas de sucesso acadêmico. Por isso, o estudante torna-se simbolicamente "excluído," após ter sido somente "incluído," integrado ao sistema de ensino superior.

Por conta da "exclusão dos incluídos" cabe questionar sobre a democratização do acesso, no interior do PROUNI, tendo como referência o fato de que a escolha pelo Curso, carreira ou profissão não tem sido uma prerrogativa do estudante. Ao abordar o fato de o estudante não fazer uma real escolha pelo Curso superior, haja vista as restrições existentes, faz-se necessário destacar a questão sobre aqueles que têm sido ofertados aos bolsistas PROUNI. Isto porque, a oferta e a procura dos estudantes dependem dos Cursos existentes nas IES parceiras do Programa, bem como de a nota do estudante ser suficiente para 
estar dentre os primeiros colocados no Curso que escolheu. Os dados podem ser consultados no Quadro 6, que expõe o percentual de Cursos acessados por bolsista PROUNI, em 2006:

\section{Quadro 6 - Percentual de alunos ingressantes em IES particulares, por cursos acessados via PROUNI no Brasil (2006)}

\begin{tabular}{|l|c|c|c|}
\hline Curso & Particular & PROUNI & FIES \\
\hline Administração & $18,5 \%$ & $18,5 \%$ & $8,2 \%$ \\
\hline Biologia & $1,4 \%$ & $1,9 \%$ & $2,4 \%$ \\
\hline Ciências Contábeis & $4,1 \%$ & $4,5 \%$ & $4,6 \%$ \\
\hline Comunicação Social & $4,5 \%$ & $4,8 \%$ & $3,2 \%$ \\
\hline Cursos tecnológicos & $1,3 \%$ & $9,9 \%$ & $2,0 \%$ \\
\hline Direito & $15,2 \%$ & $11 \%$ & $15,7 \%$ \\
\hline Enfermagem & $4,7 \%$ & $4,2 \%$ & $9,3 \%$ \\
\hline Engenharias & $5,2 \%$ & $4,6 \%$ & $4,8 \%$ \\
\hline Física & $0,02 \%$ & $0,2 \%$ & $9,3 \%$ \\
\hline Geologia & $5,3 \%$ & $4,6 \%$ & $4,8 \%$ \\
\hline Matemática & $0,1 \%$ & $1,1 \%$ & $0,004 \%$ \\
\hline Medicina & $1,1 \%$ & $0,7 \%$ & $2,4 \%$ \\
\hline Pedagogia & $5,0 \%$ & $6,8 \%$ & $1,9 \%$ \\
\hline Química & $0,3 \%$ & $0,1 \%$ & $0,5 \%$ \\
\hline
\end{tabular}

Fonte: Relatório TCU (2009), a partir da Sinopse Educação Superior 2006, SISPROUNI e SIFES.

Visualiza-se também, no Quadro 6, uma significativa diferença entre o número de ingressos de acadêmicos pagantes e bolsistas PROUNI. Um aspecto representativo emerge quando se constata que nos Cursos Tecnológicos, em 2006, foi maciça a presença de bolsistas PROUNI (9,9\%), em relação a estudantes pagantes $(1,3 \%)$, sendo uma diferença correspondente a $8,6 \%$. Chama atenção nessa questão, o fato de o PROUNI estar encaminhando os bolsistas para Cursos pouco ocupados por estudantes pagantes, nesse caso Cursos Tecnológicos, vistos por muitos como equivalentes aos tradicionais Cursos Técnicos, por possuírem duração curta, se comparados ao tempo formação em Cursos de Graduação e geralmente voltados a demandas do mercado.

Com os resultados, é possível afirmar que o encaminhamento de bolsistas PROUNI para Cursos Tecnológicos na IES privadas representa duas implicações. Primeiramente, expressa que os estudantes estão preocupados com uma 
entrada urgente no mercado de trabalho, ainda que com baixa remuneração. Ademais, esses estudantes estão sendo encaminhados para Cursos com vagas ociosas, em função da baixa procura de alunos pagantes, constituindo-se em oferta potencial de bolsas.

De forma semelhante aos Cursos Tecnológicos, no caso da Graduação, atestou-se também no Quadro 6 que o número de bolsistas é superior ao de pagantes, em Cursos tidos como complexos, embora de baixa remuneração se forem Licenciaturas, como é o caso de Matemática e Física. Ao contrário disso, observou-se um número de pagantes superior ao de bolsistas nos seguintes casos: em Cursos tradicionalmente elitizados, como Medicina e Direito, cuja oferta de bolsa PROUNI é rara, à medida que é patente a prevalência de estudantes que pertencem a famílias com alto poder aquisitivo, as quais podem pagar mensalidades e demais despesas.

Todas as constatações ora especificadas demonstram como o Programa contribui para a reprodução de acentuadas assimetrias sociais, tendo em vista as condições de acesso às IES e aos Cursos ofertados. Consequentemente, isso condiciona os projetos vocacionais dos estudantes, o que nesses casos acaba por reproduzir uma desigual distribuição dos bens educacionais, principalmente entre os estudantes das camadas populares (ALMEIDA et al., 2012).

Sobre o acesso aos Cursos, considerando aspectos que superam as questões expostas, outra problemática também pode contribuir para aumentar a restrição no tocante ao acesso a Cursos e determinados campi das IES que aderem ao Programa. A situação que ilustra isso, diz respeito a informações auditadas pela Controladoria-Geral da União (BRASIL, 2015), que por meio de uma comissão verificou in loco, a partir de uma amostra analisada no período de 2005 a 2012, nem em todos "[...] os campi geraram bolsas para os cursos que realizaram vestibulares, com consequente prejuízo no número de bolsas ofertadas ao Programa."

Para concluir os indicadores de acesso, é oportuno também destacar um problema neste aspecto, que consiste na ociosidade das bolsas PROUNI no setor privado. Esta afirmação pode ser encontrada no Relatório realizado pelo Tribunal de Contas da União (BRASIL, 2009), o qual concluiu a existência de uma crescente ociosidade das bolsas do PROUNI, chegando ao patamar de 14,88\% em 2005, e em 2010 atingindo 36,49\%, um número mais expressivo, como consta na Tabela 3 , na próxima página.

O problema da ociosidade se repete, tanto que em estudo realizado pelo MEC, por meio da equipe da Diretoria de Políticas e Programas de Graduação/ 
Secretaria de Educação Superior, com o apoio da Diretoria de Tecnologia da Informação/ Secretaria Executiva, no período entre o $1^{\circ}$ semestre de 2006 e o $1^{\circ}$ semestre de 2012, concluiu-se que "a não ocupação das bolsas do PROUNI era, em média, de $22 \%$ do total de bolsas ofertadas." (BRASIL, 2015, p. 43). Nesse sentido, esta situação instala um vício no âmbito do Programa, que pela falta de fiscalização e sanção, faz com que as IES se apropriem das verbas da isenção fiscal, ainda que mantenham bolsas ociosas.

Tabela 3 - Percentual de bolsas ociosas do PROUNI (BRASIL, 2005-2010)

\begin{tabular}{cccc}
\hline Ano & Bolsas ofertadas & Bolsas ocupadas & Vagas ociosas \\
\hline 2005 & 112.275 & 95.565 & $14,88 \%$ \\
2006 & 138.668 & 109.009 & $21,38 \%$ \\
2007 & 163.854 & 105.546 & $35,57 \%$ \\
2008 & 225.005 & 124.607 & $44,60 \%$ \\
2009 & 247.643 & 161.354 & $34,84 \%$ \\
2010 & 240.441 & 152.697 & $36,49 \%$ \\
$2005 / 2010 \Delta(\%)$ & $114,15 \%$ & $59,78 \%$ & - \\
\hline
\end{tabular}

Fonte: Relatório do TCU/MEC/SISPROUNI

\section{- Indicadores de permanência no PROUNI:}

O indicador que se escolheu neste estudo para analisar o grau de permanência, por parte do estudante que usufrui da bolsa foi o Índice de Conclusão dos Cursos (ICC). Segundo dados prestados pelo Serviço de Informação ao Cidadão, "do total de estudantes beneficiados pelo PROUNI até 2012, 277.912 concluíram o Curso Superior" (BRASIL/MEC, 2013). Sobre esse número de concluintes, nota-se que é relativamente inferior ao de bolsistas matriculados em 2007, que perfez um total 310.186 estudantes. Ao calcular o Índice de Evasão Total (IET) - utilizou-se o número de ingressantes dividido pela quantidade de concluintes num determinado período -, obtém-se que em 2012, prazo estimado para que os bolsistas matriculados em 2007 concluíssem o Curso, 32.274 $(10,4 \%)$ não conseguiram concluir.

Para efeito de análise, quando se tem como parâmetro o IET entre o setor público e o privado, no período de 2006 a 2011, registrou-se que no PROUNI tal índice é baixo. Isto porque 102.741 estudantes $(34,4 \%)$ foi o Índice 
de Evasão no setor público, enquanto no setor privado contabilizou 480.607 estudantes $(41,7 \%)$ que não finalizaram o Curso no período estipulado. Desse modo, é elevada a evasão total nos setores público e privado, no Brasil, quando comparada à dos bolsistas PROUNI (10,4\%), provavelmente em função de a vigência da bolsa ser de tempo determinado, condicionado à duração do Curso, exceto os casos de trancamento por tempo determinado, o que difere da flexibilidade relativa que os estudantes do setor público e privado (pagantes) têm de integralizar o Curso.

O dado apresentado quanto à conclusão dos Cursos corresponde a mais um indicador para analisar o tipo de inclusão destinada ao bolsista do Programa, o qual mostra que parcela dos estudantes mesmo incluídos ao ter uma vaga, não têm integralizado o Curso superior. Este problema demonstra a possível situação de exclusão destes bolsistas, que não têm as condições ideais de estudo que possam assegurar a permanência, pois encontram dificuldades que não são resolvidas somente com bom desempenho acadêmico, todavia dependem de outros incentivos.

Afinal, mesmo com o fato de o PROUNI arcar com as mensalidades, fica a questão de como os mais pobres poderão superar o fato de nas IES privadas serem inexistentes auxílio para moradia, alimentação e bolsas-auxílio, embora tal assistência seja requisito fundamental, em especial para o perfil dos estudantes selecionados. Nesse sentido, Takahashi (2004) ressalta que os próprios representantes das mantenedoras e os estudantes criticam as condições de permanência, pois a renda per capita exigida impossibilita que o estudante se mantenha na Universidade/faculdade.

Ao contrário da ausência de políticas internas nas IES privadas, voltadas para assistência estudantil a alunos de baixa renda, como é o caso dos bolsistas do PROUNI, à exceção das bolsas-permanência, cabe destacar que as Instituições Federais de Ensino Superior têm histórico de buscar ações que visam ampliar as condições de permanência dos estudantes. Tais ações, por exemplo, surgem no período que compreende a implantação do PROUNI, quando se criou o Programa Nacional de Assistência Estudantil (PNAES), em dezembro de 2007, instituído pela Portaria Normativa n. 39/ MEC, desde 2008. Falar sobre o PNAES é oportuno por se tratar de uma medida governamental para atender ao público-alvo nas IFES, que possui as mesmas características do bolsista PROUNI, os quais poderiam ter garantidas ações destinadas para sua permanência, haja vista constarem no âmbito do Programa, mas estão desassistidos pelo Governo Federal e pelas IES privadas. 


\section{Considerações Finais}

As análises efetuadas revelam que o PROUNI possui limitações em sua capacidade de controlar a ocupação das bolsas, de forma que entre 2005 e 2009 não havia qualquer normatização obrigando o preenchimento das bolsas ociosas, problema ainda presente em 2012, quando já havia regulamentação. Nesse sentido, mesmo com as bolsas ociosas, as IES foram isentas de todos os tributos integralmente previstos na Lei n. 11.096/2005. O preocupante é que os recursos isentos pelo Estado deixaram de ser arrecadados, sem a certeza de preenchimento das bolsas nas IES, pelos estudantes. Isso representa desperdícios sociais, acadêmicos e econômicos, de recursos públicos investidos sem o devido retorno (SILVA FILHO et al., 2007).

Em linhas gerais, verifica-se que o PROUNI propicia: a) preenchimento de vagas ociosas geradas pela falta de alunos pagantes nas IES privadas; b) isenção fiscal às IES parceiras, desobrigando-as até mesmo de quase todos os tributos federais, como é o caso das IES com fins lucrativos; c) encaminhamento de bolsistas para Cursos de menor concorrência, atendendo a um público que sequer ingressaria em IES privadas, haja vista as restrições financeiras para arcar com as mensalidades.

Conclui-se, com estes resultados, que existem fatores a se considerar para o debate acerca dos dados relacionados ao PROUNI, sendo eles: 1) Uma residual parcela da população tem tido bolsa para ingressar na Educação Superior; 2) A renúncia fiscal beneficia as IES privadas, e diminui a pressão no Governo Federal de arcar com a abertura de novas vagas nas IES públicas; 3) O volume da isenção fiscal acumulado entre 2006 a 2012 é tão significativo que poderia sustentar todas as IFES integralmente durante um ano, ainda com saldo significativo; 4) A distribuição dos bens educacionais entre os bolsistas PROUNI e acadêmicos pagantes é desigual, dirigindo os estudantes das camadas populares geralmente a Cursos pouco procurados e de baixa qualidade.

Por todos os resultados analisados, cabe problematizar se o Programa contribui efetivamente com a democratização do acesso e da permanência na Educação Superior brasileira nas atuais condições. Isso também desperta para o fato de se problematizar as atuais políticas neste nível de ensino e também se cogitar a criação de uma política alternativa ao PROUNI, que assegure e garanta o ingresso dos estudantes que advêm das camadas populares. Para tanto, acredita-se que a garantia do aumento de vagas nas IES públicas é favorável à expansão deste nível de ensino, devendo-se fortalecer medidas desta natureza enfraquecendo aquelas que estimulem a privatização, como é o caso do Pro- 
grama, que termina subsidiando o setor privado com volumosa isenção fiscal, em detrimento da arrecadação de tributos, que deveriam fortalecer erário, para investimento público no ensino público e gratuito.

\section{Referências}

AMARAL, Nelson C. O financiamento das IFES Brasileiras e o custo aluno em FHC e Lula. In: ENCONTRO DA ANPED, 34., 2011, Natal. Anais... Natal, 2011. Disponível em: <http://www.anped11.uerj.br/GT11-505\%20int. pdf>, 2011. p. 6 .

ALMEIDA, Leandro et al. Democratização do acesso e do sucesso no ensino superior: uma reflexão a partir das realidades de Portugal e do Brasil. Avaliação, Campinas; Sorocaba, v. 17, n. 3, p. 899-920, nov. 2012. Disponível em: $<\mathrm{http}: / / w w w . s c i e l o . b r / s c i e l o . p h p ? p i d=S 1414-$ $40772012000300014 \&$ script=sci_arttext $>$. Acesso em: 18 nov. 2011.

BRASIL. Controladoria Geral da União. Relatório de avaliação da execução de Programas de Governo n. 35: Programa Universidade Para Todos - PROUNI. Brasília: CGU, 2015.

BRASIL. Lei n. 11.096, 13 de janeiro de 2005. Institui o Programa Universidade para Todos (PROUNI), regula a atuação de entidades beneficentes de assistência social no ensino superior, altera a Lei n. 10.981, de 9 de julho de 2004, e dá outras providências. Diário Oficial [da] República Federativa do Brasil, 14 jan. 2005. Disponível em: $<\mathrm{http} / /$ www.in.gov.br>. Acesso em: 14 dez. 2010.

BRASIL. Ministério da Educação. Secretaria de Educação Superior. Revista PROUNI, Brasília, DF, n. 1, 2008.

BRASIL. Tribunal de Contas da União. Relatório de auditoria operacional: Programa Universidade para Todos (ProUni) e Fundo de Financiamento ao Estudante do Ensino Superior (FIES). Relator: Ministro José Jorge. Brasília: TCU, 2009.

BRASIL. Tribunal de Contas da União. Relatório de monitoramento: Acórdãos n. 816/2009 e 2043/2010 - Auditorias operacionais nos Programas PROUNI e FIES (segunda avaliação). Relator Ministro José Jorge. Brasília: TCU, 2013. 
BRASIL. Instituto Nacional de Estudos e Pesquisas Educacionais Anísio Teixeira. Sinopses Estatísticas da Educação Superior: Graduação (2005). 2005.Disponível em: <http://portal.inep.gov.br/web/guest/sinopsesestatisticas-da-educacao-superior>. Acesso em: 12 fev. 2012.

BRASIL. Instituto Nacional de Estudos e Pesquisas Educacionais Anísio Teixeira. Sinopse Estatística da Educação Superior: Graduação (2006). 2006. Disponível em: $<$ http://portal.inep.gov.br/web/guest/sinopsesestatisticas-da-educacao-superior>. Acesso em: 12 fev. 2012.

BRASIL. Instituto Nacional de Estudos e Pesquisas Educacionais Anísio Teixeira. Sinopse Estatística da Educação Superior: Graduação (2007). 2007. Disponível em: <http://portal.inep.gov.br/web/guest/sinopsesestatisticas-da-educacao-superior>. Acesso em: 12 fev. 2012.

BRASIL. Instituto Nacional de Estudos e Pesquisas Educacionais Anísio Teixeira. Sinopse Estatística da Educação Superior: Graduação (2008). 2008. Disponível em: <http://portal.inep.gov.br/web/guest/sinopsesestatisticas-da-educacao-superior>. Acesso em: 12 fev. 2012.

BRASIL. Instituto Nacional de Estudos e Pesquisas Educacionais Anísio Teixeira. Sinopse Estatística da Educação Superior: Graduação (2009). 2009. Disponível em: $<$ http://portal.inep.gov.br/web/guest/sinopsesestatisticas-da-educacao-superior>. Acesso em: 12 fev. 2012.

CARVALHO, Cristina H. A. de. Política de ensino superior e renúncia fiscal: da reforma universitária de 1968 ao PROUNI. In: ENCONTRO DA ANPED; GT - Política de educação superior, 28., Caxambu. Anais... Caxambu: ANPEd, 2005. p.1-17.

CARVALHO, Cristina H. A.; LOPREATO, Francisco L. C. Finanças públicas, renúncia fiscal e o PROUNI no governo Lula. Impulso, Piracicaba, v. 16, n. 40, p. 93-104, maio/ago. 2005.

CASTRO, Grasielle; MARIZ, Renata. ProUni oferece curso reprovado pelo MEC. Estado de Minas, Belo Horizonte, 20 jan. 2013. Caderno Educação. Disponível em: <http://www.em.com.br/app/noticia/especiais/ educacao/2013/01/20/internas_educacao,344668/prouni-oferece-cursoreprovado-pelo-mec.shtml>. Acesso em: 14 fev. 2013.

CHAVES, Vera Lucia Jacob. Expansão e privatização/ mercantilização do ensino superior brasileiro: a formação dos oligopólios. Educação e 
Sociedade, Campinas, v. 31, n. 111, p. 481-500, abr.jun. 2010. Disponível em: <http://www.scielo.br/pdf/es/v31n111/v31n 111a10.pdf. Acesso em: 20 fev. 2012.

FABRINI, Fábio; WEBER, Demétrio. ProUni: bolsas não chegam a alunos. O Globo, 13 mar. 2011. Disponível em: <http://www.andes.org.br/andes/ print-ultimas-noticias.andes?id=4471>. Acesso em: 12 jun. 2012.

GUERRA, Lenin C. B.; FERNANDES, Antonio S.A. O processo de criação do Programa Universidade para Todos (PROUNI): interesses e escolhas no Congresso nacional. Revista Política Hoje, Recife, v. 18, n. 2, 2009. Disponível em: $<$ http://www.revista.ufpe.br/politicahoje/index.php/politica/ article/viewArticle/32>. Acesso em: 12 ago. 2012.

LEHER, Roberto. Educação no governo de Lula da Silva: a ruptura que não aconteceu. In: LEHER, Roberto. Os anos Lula: contribuições para um balanço crítico (2003-2010). Rio de Janeiro: Garamond, 2010.

LIMA, Kátia R. R.; PRADO, Francisco. H. S.; VIEIRA, R. B. Políticas públicas de "democratização" da Educação Superior no Governo Lula: ENEM, PROUNI, REUNI. In: ENCONTRO BRASILEIRO DE EDUCAÇÃO E EMANCIPAÇÃO HUMANA, 5., 2011, Florianópolis. Anais... Florianópolis: UFSC, v.5, n.1, p.1-14, 2011.

MANCEBO, Daise. Universidade para todos: a privatização em questão. Pro-Posições, Campinas, v. 15, n. 3, p. 75-90, 2004. Disponível em: <www. proposicoes.fe.unicamp.br/ proposicoes/.../45-dossie-\%20mancebod.pdf $>$. Acesso em: 12 abr. 2011.

PEREIRA FILHO, Ednaldo da S. Perfil de jovens universitários bolsistas PROUNI: um estudo de caso na Unisinos. 2011, $131 \mathrm{f}$. Tese (Doutorado em Ciências Sociais) - Universidade do Vale do Rio dos Sinos, São Leopoldo, 2011.

SILVA FILHO, Roberto. L. L. et al. A evasão no ensino superior brasileiro. Cadernos de Pesquisa, São Paulo, v. 37, n. 132, set./dez. 2007.

TAKAHASHI, Fábio. Prouni pode ter meia bolsa e vestibular a beneficiados. Folha Online, 1, jul. 2004. Educação. Disponível em: $<$ http://www1.folha. uol.com.br/>. Acesso em: 18 jun. 2011.

ZAGO, Nadir. Do acesso à permanência no Ensino Superior: percursos de estudantes universitários de camadas populares. Revista Brasileira de Educação, Rio de Janeiro, v. 11, n. 32, maio/ago. 2006. 
Danielle Dias da Costa - Universidade do Estado do Amapá Macapá | AP | Brasil. Contato: ddcosta.ueap@gmail.com

Norma-Iracema de Barros Ferreira - Universidade Federal do Amapá Macapá | AP | Brasil. Contato: normairacema@unifap.br

Artigo recebido em 4 de agosto de 2015 e aprovado em 22 de fevereiro de 2016. 
